\title{
PROFIL USAHA KLAPERTAART MANADO
}

\author{
Crystalinda T. O Mekel \\ Jenny Baroleh \\ Caroline B. D Pakasi
}

\begin{abstract}
This study aims to provide a description of the Petra klapertaart business in terms of raw materials, capital, labor, production, costs, and the amount of profit earned.This research was conducted for one mounth on October 2015. The data used are primary data get from the owner. Petra klapertaart is one of the home industries that can give value added to coconut plants, particularly coconuts, so it can help coconut farmers to improve their economy. Constraints limited capital to run the business, get solution from the Ministry of Agriculture that is Petra klapertaart registered as one of a member the Independent Institute Rooted in the Community (LM3), which receive capital assistance in the form of funds. This led to make a research to see the description of the business profile Petra klapertaart after getting financial aid from the Ministry of Agriculture. Data obtained with primary data taken by researchers from business owners as the the main source. Data collection techniques were done by direct observation and interviews with business owners. The results showed that the Petra klapertaart business is a small-scale business that uses coconut raw materials that processed into klapertaart and became one of the members of the Independent Institute Rooted in the Community (LM3) which get funding. On Klapertaart marketing activities, business owners deal directly with consumers to sell klapertaart. Based on the results, the amount of production, the amount of production in September 2015, which is 12 times the production made two recipes in each production, produce 348 klapertaart cup aluminum foil, make a profit with the ratio of $R / C>1$ is equal to 1.84 in September 2015 means, Petra business get the benefits, so this business is effort to develop
\end{abstract}

Keywords: Company Profile, Klapertaart, Profit

\begin{abstract}
ABSTRAK
Penelitian ini bertujuan untuk memberikan Gambaran tentang usaha Petra klapertaart dalam hal bahan baku, modal, tenaga kerja, produksi, biaya, dan besarnya keuntungan yang diperoleh. Data diperoleh dengan data primer yang diambil oleh peneliti dari sumber utama yakni pemilik usaha Petra klapertaart. Teknik pengumpulan data yang digunakan dengan cara Observasi langsung dan wawancara dengan pemilik usaha. Hasil penelitian menunujukan bahwa Usaha Petra klapertaart merupakan usaha berskala kecil yang menggunakan bahan baku buah kelapa untuk diolah menjadi klapertaart dan menjadi salah satu anggota dari Lembaga Mandiri yang Mengakar di Masyarakat (LM3) yang mendapatkan bantuan modal. Pada kegiatan pemasaran klapertaart, pemilik usaha berhadapan langsung dengan konsumen untuk menjual klapertaart yang dihasilkan. Berdasarkan hasil penelitian, banyaknya produksi pada bulan September 2015 yaitu 12 kali produksi yang dibuat 2 resep pada setiap kali produksi, menghasilkan 348 cup aluminium foil klapertaart, memperoleh keuntungan dengan rasio R/C >1 yaitu sebesar 1,84 artinya pada bulan September 2015 usaha Petra mengalami keuntungan sehingga usaha ini layak diusahakan.
\end{abstract}

Kata Kunci: Profil Usaha, Klapertaart, Keuntungan 


\section{PENDAHULUAN}

\section{Latar Belakang}

Sektor pertanian sangat berperan dalam kehidupan manusia, khususnya di bidang pangan dalam memenuhi kebutuhan hidup. Petani mengupayakan serangkaian kegiatan dalam pertanian, baik dalam mempersiapkan lahan yang akan diolah seperti membajak sawah, mengelola tanaman yang dibudidayakan hingga tanaman yang dibudidayakan tersebut memberikan hasil pertanian yang bermutu tinggi.

Selain sebagai sumber penghasil bahan pokok, sektor pertanian juga berperan pada bidang sosial dan ekonomi yang dapat dilihat dalam hal menyediakan lapangan kerja, mengurangi ketergantungan terhadap impor dan memberikan nilai tambah bagi komoditi pertanian. Agar hal tersebut dapat direalisasikan, maka pengembangan agroindustri sangat diperlukan. Menurut Wirakartakusumah, keberadaan industri pangan di Indonesia dapat menyerap tenaga kerja dalam jumlah yang cukup banyak serta mampu mendorong berdirinya industri penunjang seperti pengolahan makanan dan minuman.

Di Sulawesi Utara, jenis tanaman perkebunan yang memiliki luas lahan terbesar adalah tanaman kelapa, sehingga Sulawesi Utara dikenal dengan daerah 'Nyiur Melambai'. Hal ini dapat dilihat pada besarnya lahan untuk tanaman kelapa yang seluas 2.803.000 Ha, dibandingkan dengan tanaman Kopi yang hanya seluas $81.000 \mathrm{Ha}$, dan kakao seluas 183.000 Ha (Badan Pusat Statistik, 2013).

Sekarang ini, sudah banyak usaha yang dijalankan menggunakan bahan baku hasil pertanian yang diolah menjadi bahan pangan. Baik sebagai kudapan atau camilan, maupun sebagai makanan pokok, dan makanan pembuka, serta makanan penutup. Salah satunya adalah olahan bahan pangan yang terbuat dari bahan baku kelapa.

Dalam menjalankan suatu usaha diperlukan modal, karena modal merupakan salah satu faktor yang mempengaruhi kelancaran produksi. Kurangnya modal yang dimiliki, menjadi salah satu kendala yang sering dihadapi bagi pelaku usaha. Dalam rangka mengatasi permodalan yang lemah,
Kementerian Pertanian melaksanakan salah satu program pembangunan pertanian melalui Lembaga Mandiri yang Mengakar di Masyarakat (LM3), dengan harapan mampu mengelola dan memanfaatkan sumber daya yang ada, serta menjadi mitra Kementerian Pertanian.

Usaha Petra merupakan industri rumah tangga yang mengolah daging kelapa menjadi klapertaart. Sebelum pemasangan nama usaha Petra klapertaart, pemilik usaha melakukan uji coba resep dengan modal yang terbatas pada pembuatan klapertaart, produksi yang dilakukan hanya sedikit karena tergantung pada pesanan, pemakaian peralatan yang dimiliki pribadi tidak lengkap. Hasil uji coba resep tersebut, dijual kepada para kolega yang memesan klapertaart khas dari kota Manado. Klapertaart yang dibuat oleh pemilik usaha mendapatkan tanggapan yang baik, sehingga mendorong pemilik usaha untuk membuka usaha dengan menjual klapertaart buatannya dan meminta bantuan modal dari pemerintah.

\section{Deskripsi Buah Kelapa}

Kelapa (Cocos nucifera L.) adalah salah satu jenis tumbuhan dari suku aren-arenan atau pinang-pinangan atau Arecaceae dan merupakan anggota tunggal dalam marga Cocos. Kelapa juga adalah sebutan untuk buah yang dihasilkan tumbuhan ini. Buah kelapa besar, berdiameter $10 \mathrm{~cm}$ sampai $20 \mathrm{~cm}$ atau bahkan lebih, berwarna kuning, hijau, atau coklat. Buah tersusun dari mesokarp berupa serat yang berlignin, disebut sabut, melindungi bagian endokarp yang keras (disebut batok) dan kedap air, endokarp melindungi biji yang hanya dilindungi oleh membran yang melekat pada sisi dalam endokarp. Endospermium berupa cairan yang mengandung banyak enzim, dan fase padatannya mengendap pada dinding endokarp seiring dengan semakin tuanya buah; embrio kecil dan atau baru membesar ketika buah siap untuk berkecambah (disebut kentos).

Bagian buah kelapa bernilai ekonomi, seperti pada sabut, bagian mesokarp yang berupa serat-serat kasar, diperdagangkan sebagai bahan bakar, pengisi jok kursi, anyaman tali, keset. Serta media tanam bagi anggrek. Tempurung atau batok, 
yang sebetulnya adalah bagian endokarp, dipakai sebagai bahan bakar, pengganti gayung, wadah minuman, dan bahan baku berbagai kerajinan tangan.

Endosperma buah kelapa yang cairan endapannya yang melekat di dinding dalam batok ("daging buah kelapa") berwarna putih dan lunak. Cairan ini mengandung beraneka enzim dan memiliki khasiat penetral racun dan efek penyegar. Beberapa kelapa bermutasi sehingga endapannya tidak melekat pada dinding batok melainkan tercampur dengan cairan endosperma. Mutasi ini disebut kelapa kopyor. Daging buah tua kelapa berwarna putih dan mengeras. Sarinya diperas dan cairan dinamakan santan. Daging buah tua ini juga dapat diambil dan dikeringkan serta menjadi komoditi perdagangan bernilai ekonomis yang disebut kopra. Kopra adalah bahan baku pembuatan minyak kelapa dan turunannya. Cairan buah tua biasanya tidak menjadi bahan minuman penyegar melainkan limbah industri kopra. Namun, cairan ini dapat dimanfaatkan lagi untuk dibuat menjadi bahan semacam jelly yang disebut nata de coco dan merupakan bahan campuran minuman penyegar. Daging buah kelapa juga dapat dimanfaatkan sebagai obat rambut yang rontok dan mudah patah.

\section{Klapertaart}

Klapertaart adalah kue yang terbuat dari berbahan dasar buah kelapa, tepung terigu, susu, mentega dan telur. Berasal dari kata "klapa" yang berarti kelapa dan "taart" yang berarti kue tart. Resep kue ini merupakan peninggalan jaman Belanda, hingga saat ini klapertaart menjadi salah satu kuliner yang paling terkenal dari Manado.

Terdapat berbagai cara dalam pembuatan kue klapertaart. Ada yang dipanggang yang menghasilkan tekstur yang padat dan ada juga yang tidak dipanggang yang menghasilkan tekstur yang lembut. Klapertaart biasanya tidak bertahan lama. Karena itu, klapertaart harus disimpan di lemari pendingin agar tidak cepat rusak.

Klapertaart disajikan dalam bermacammacam rasa. Beberapa diantaranya seperti rasa original, ubi jalar, dan durian (tersedia pada saat musimnya) dengan berbagai ukuran dan harga yang ditawarkan.

\section{Agroindustri dan Industri Rumah Tangga}

Agroindustri adalah kegiatan yang memanfaatkan hasil pertanian sebagai bahan baku, merancang dan menyediakan peralatan serta jasa untuk kegiatan tersebut. Menurut Soewono (2005), dengan pertanian sebagai pusatnya, agroindustri merupakan sektor ekonomi yang meliputi semua perusahaan, agen dan institusi yang menyediakan segala kebutuhan pertanian dan mengambil komoditas dari pertanian untuk diolah dan didistribusikan kepada konsumen. Nilai strategis agroindustri terletak pada posisinya sebagai jembatan yang menghubungkan antar sektor pertanian pada kegiatan hulu dan sektor industri pada kegiatan hilir.

Menurut Siahaan (1996), ada beberapa kriteria dalam klasifikasi industri. Industri rumah tangga merupakan salah satu dari klasifikasi industri berdasarkan jumlah tenaga kerja. Industri ini menggunakan tenaga kerja tidak lebih dari 4 orang. Ciri dari industri memiliki modal yang sangat terbatas, tenaga kerja yang berasal dari anggota keluarga, dan pemilik atau pengelola industri biasanya berperan sebagai kepala rumah tangga itu sendiri atau anggota keluarganya. Dalam proses produksi, biasanya masih menggunakan teknologi yang sederhana, memperkerjakan anggota keluarga atau warga sekitar dan berorientasi pada pasar. Ada bermacam pilihan untuk jenis usaha yang akan dijalankan pada industri rumah tangga. Salah satunya dalam bidang pengolahan makanan yang sering dijadikan sebagai peluang usaha.

\section{Lembaga Mandiri yang Mengakar di Masyara- kat (LM3)}

Lembaga Mandiri yang Mengakar di Masyarakat (LM3) adalah lembaga sasaran yang telah menjalankan usaha agribisnis dengan prioritas yang memiliki potensi sumber daya usaha pertanian yang memadai untuk diberikan bantuan modal berupa dana. Lembaga ini tumbuh dan berkembang di masyarakat dengan kegiatan meningkatkan gerakan moral melalui kegiatan pendidikan dan keterampilan untuk meningkatkan kesejahteraan masyarakat, juga memberdayakan kelembagaan keagamaan, antara lain Pondok Pesantren, Semi- 
nari, Paroki dan Gereja, Pasraman, Vihara, Subak. Program pemberdayaan dan pengembangan usaha agribisnis Lembaga Mandiri yang Mengakar di Masyarakat (LM3) menjadi salah satu strategi pembangunan pertanian yang dirintis untuk mengentaskan masyarakat dari kemiskinan dan pengangguran.

Tujuan pemberdayaan dan pengembangan usaha agribisnis LM3 secara khusus:

a) Mendorong tumbuhnya LM3 sebagai embrio pembentukan inti kawasan agribisnis

b) Mengembangkan usaha agribisnis dan agroindustri di sekitar lokasi LM3

c) Mengembangkan kemitraan dan jaringan kerjasama agribisnis terpadu

d) Meningkatkan pendapatan dan kesejahteraan masyarakat di sekitar LM3.

Sasaran pemberdayaan dan pengembangan usaha agribisnis LM3 secara umum:

a) Menguatnya modal usaha LM3 dalam mengembangkan usaha agribisnis

b) Meningkatnya kemampuan dan kapasitas sumber daya manusia serta kelembagaan usaha agribisnis LM3

c) Meningkatnya produksi, produktivitas usaha, mutu, daya saing, nilai tambah dan pendapatan LM3 serta masyarakat sekitarnya di bidang agribisnis

d) Berkembangnya usaha agribisnis termasuk diversifikasi usaha dan agroindustri di LM3 serta masyarakat sekitarnya

e) Meningkatnya pengetahuan dan keterampilan para santri/anggota LM3 di bidang agribisnis

f) Meningkatnya kemandirian dan jaringan kerjasama LM3 dengan para stakeholder agribisnis.

\section{Faktor Yang Mempengaruhi Produksi}

Menurut Kotler dan Amstrong (2001), produk adalah segala sesuatu yang dapat ditawarkan ke pasar untuk mendapatkan perhatian, dibeli, digunakan, atau dikonsumsi yang dapat memuaskan keinginan atau kebutuhan. Menurut Assauri (1995), produksi adalah kegiatan untuk menciptakan atau menambah kegunaan barang atau jasa. Menurut Ahyari (2002), proses produksi adalah suatu cara, metode ataupun teknik menambah kegunaan suatu barang dan jasa dengan menggunakan faktor produksi yang ada. Menurut Griffin (2006) secara total, saat ini ada lima hal yang dianggap sebagai faktor produksi, yaitu:

\section{Sumber Daya Fisik}

Faktor produksi fisik ialah semua kekayaan yang terdapat di alam semesta dan barang mentah lainnya yang dapat digunakan dalam proses produksi. Dalam hal ini, faktor sumber daya fisik berupa hasil pertanian yang menjadi bahan baku. Diperlukan bahan baku dalam mengolah menjadi suatu produk.

\section{Tenaga Kerja}

Faktor produksi tenaga kerja menggunakan tenaga dari manusia atau biasa disebut sumber daya manusia. Dalam faktor ini ada pengelompokan tersendiri bagi tenaga kerja, yaitu:

a) berdasarkan sifatnya, yaitu:

(1) Tenaga kerja jasmani.

Seluruh kegiatan atau aktivitas pekerjaan yang dilakukan lebih banyak menggunakan kekuatan fisik.

(2) Tenaga kerja rohani.

Kegiatan yang dilakukan lebih banyak menggunakan otak atau pikiran.

b) berdasarkan kualitas atau kemampuan:

(1) Tenaga kerja terdidik, tenaga kerjanya membutuhkan pendidikan yang sesuai.

(2) Tenaga kerja terampil, tenaga kerja ini dibutuhkan yang berpengalaman, terlatih dan biasanya mengikuti kursus sebelumnya.

(3) Tenaga kerja tidak terdidik dan tidak terampil yang biasa disebut tenaga kerja kasar, tenaga kerja yang tidak membutuhkan keahlian dan pendidikan khusus.

Jadi, faktor tenaga kerja manusia juga sangat berpengaruh, karena manusia yang menentukan tujuan dan menjalankan prosesnya agar tujuan tercapai. 


\section{Modal}

Modal adalah harta yang dimiliki untuk digunakan dalam suatu proses produksi sehingga diharapkan bisa menghasilkan pendapatan. Modal memiliki peranan penting dalam proses pengadaan barang dan jasa. Ada beberapa pembagian modal, yaitu:

a) berdasarkan sifatnya:

(1) Modal tetap, bisa digunakan beberapa kali atau berulang-ulang.

(2) Modal lancar, hanya bisa digunakan sekali saja.

b) berdasarkan sumbernya:

(1) Modal sendiri, bersumber dari suatu perusahaan milik bersama ataupun pribadi

(2) Modal asing, bersumber dari pinjaman bank atau berasal dari luar perusahaan.

c) berdasarkan kepemilikan:

(1) Modal individu, modal yang bersumber dari dari perorangan yang hasilnya merupakan sumber pendapatan bagi si pemilik.

(2) Modal umum, modal yang berasal dari pemerintah yang digunakan untuk kepentingan bersama.

d) berdasarkan bentuknya:

(1) Modal konkret yang berbentuk nyata

(2) Modal abstrak yang tidak memiliki bentuk, tapi memiliki nilai tersendiri.

Kewirausahaan

Faktor kewirausahaan adalah keahlian atau keterampilan yang digunakan seseorang dalam mengkoordinir faktor-faktor produksi untuk menghasilkan barang dan jasa. Sebanyak dan sebagus apapun faktor produksi daya alam/fisik, tenaga kerja, serta modal yang dipergunakan dalam proses produksi, jika dikelola dengan tidak baik, maka hasilnya tidak akan maksimal.

Dalam buku "Principles of Management", George R Terry (1978) menjelaskan bahwa dalam menjalankan suatu usaha diperlukan perencanaan, pengorganisasian, pengarahan, pengawasan, dan evaluasi.
Sumber Daya Informasi

Sumber daya informasi adalah seluruh data yang dibutuhkan perusahaan untuk menjalankan bisnisnya. Data ini bisa berupa ramalan kondisi pasar, pengetahuan yang dimiliki karyawan, dan data-data ekonomi lainnya.

\section{Konsep Biaya, Penerimaan, Keuntungan}

\section{Biaya}

Menurut Mursyidi (2008), biaya adalah suatu pengorbanan yang dapat mengurangi kas atau harta lainnya untuk mencapai tujuan, baik yang dapat dibebankan pada saat ini maupun pada saat yang akan datang. Dalam menjalankan suatu usaha sudah pasti ada biaya yang harus dikeluarkan, mulai dari memproduksi hingga memasarkan hasil produksi.

Biaya produksi adalah semua pengeluaran ekonomis yang harus dikeluarkan untuk memproduksi suatu barang. Biaya dapat digolongkan berdasarkan hubungannya dengan volume aktivitas, yaitu:

1. Biaya Tetap (Fixed Cost)

Biaya yang umumnya tetap konstan, tidak dipengaruhi oleh perubahan volume atau aktivitas sampai dengan tingkatan tertentu.

2. Biaya Variabel (Variable Cost)

Biaya yang jumlah totalnya berubah secara sebanding dengan perubahan volume kegiatan atau aktivitas.

Penjumlahan dari biaya tetap dan biaya variabel adalah biaya total (TC) dapat dirumuskan sebagai berikut:

$$
T C=T F C+T V C
$$

Dimana :

TC =Total Cost (Total Biaya)

TFC =Total Fixed Cost (Total Biaya Tetap)

TVC =Total Variable Cost $($ Total Biaya Variabel)

Penerimaan (Revenue)

Menurut Nicholson (1994), penerimaan adalah jumlah/kuantitas barang yang terjual 
dikalikan dengan harga barang tersebut. Semakin banyak yang terjual, semakin banyak pula total penerimaan.

Untuk menghitung penerimaan dengan menggunakan rumus matematis sebagai berikut:

$$
T R=P \cdot Q
$$

Dimana :

TR =Total Revenue (Total Penerimaan)

$\mathrm{P} \quad=$ Price (Harga Produk)

$\mathrm{Q} \quad=$ Quantity (Jumlah Produk)

\section{Keuntungan}

Keuntungan adalah total penerimaan dikurangi total biaya. Keuntungan dalam suatu usaha dapat dilihat dari hasil yang diterima setelah mengurangi total penerimaan dengan total biaya yang ada. Keuntungan dalam suatu usaha atau industri dapat menggunakan rumus:

$$
\pi=T R-T C
$$

Dimana :

$$
\begin{aligned}
& \pi \quad=\text { Profit atau keuntungan } \\
& \mathrm{TR}=\text { Total Revenue (Total } \\
& \text { Penerimaan) } \\
& \mathrm{TC} \quad=\text { Total Cost (Total Biaya) }
\end{aligned}
$$

Menurut Darsono dalam Sari, R/C rasio merupakan metode analisis untuk mengukur kelayakan usaha dengan menggunakan rasio penerimaan (revenue) dan biaya (cost). Analisis kelayakan usaha digunakan untuk mengukur tingkat pengembalian usaha.

\section{Perumusan Masalah}

Usaha klapertaart di Manado sudah sering dijumpai dengan berbagai macam penawaran yang diberikan. Salah satu usaha yang memproduksi klapertaart adalah Petra klapertaart. Dalam menjalankan usaha ini, Petra klapertaart menghadapi kendala yaitu terbatasnya modal yang dimiliki dan meminta bantuan dari Kementerian Pertanian sehingga mendapatkan bantuan dalam hal permodalan. Hal ini mendorong diadakannya penelitian untuk melihat gambaran dari profil usaha Petra klapertaart setelah mendapatkan bantuan modal dari Kementerian Pertanian.

\section{Tujuan Penelitian}

Penelitian ini bertujuan untuk mengetahui profil tentang usaha Petra klapertaart dalam hal bahan baku, modal, tenaga kerja, produksi, biaya, dan besarnya keuntungan yang diperoleh, setelah mendapatkan bantuan modal dari LM3.

\section{Manfaat Penelitian}

Hasil penelitian ini diharapkan dapat memberikan Gambaran mengenai profil usaha Petra klapertaart. Adapun manfaat lain dari penelitian ini:

a) Bagi pelaku usaha Petra klapertaart dapat digunakan sebagai informasi dalam mengelola dan meningkatkan usaha dalam mencapai keuntungan yang maksimal.

b) Bagi peneliti bermanfaat dalam menambah wawasan dan pengetahuan mengenai usaha industri rumah tangga pangan, khususnya dalam usaha klapertaart.

c) Bagi pembaca diharapkan menambah pengetahuan tentang profil suatu usaha dan konsep tentang bisnis atau usaha di bidang agribisnis.

\section{METODOLOGI PENELITIAN}

\section{Waktu dan Tempat Penelitian}

Penelitian ini dilakukan selama bulan Oktober 2015 mulai dari persiapan sampai pada penyusunan laporan. Penelitian ini telah dilakukan di usaha Petra klapertaart yang berlokasi di Jl. Babe Palar No. 80, Manado.

\section{Teknik dan Pengumpulan Data}

Dalam penelitian ini, data yang dikumpulkan adalah data primer yang diambil oleh peneliti dari sumber utama yakni pemilik usaha Petra klapertaart. Teknik pengumpulan data yang digunakan sebagai berikut:

a. Observasi.

Peneliti melakukan pengamatan secara langsung pada usaha Petra klapertaart.

b. Wawancara.

Peneliti melakukan dialog langsung dengan pemilik usaha dengan mempersiapkan terlebih dahulu daftar pertanyaan yang akan diberikan kepada pemilik usaha. 


\section{Konsep Pengukuran Variabel}

Hal-hal yang akan diteliti pada profil usaha Petra klapertaart:

a. Karakteristik pengusaha, umur, pendidikan

b. Sejarah usaha, bentuk usaha, modal.

c. Manajemen, struktur organisasi, perijinan.

d. Produksi: proses produksi, jenis produk, kemasan.

e. Bahan baku: sumber bahan baku, ketersediaan bahan baku, jumlah bahan baku yang dipakai dalam produksi klapertaart.

f. Tenaga kerja, jumlah tenaga kerja yang dipekerjakan.

g. Bangunan dan peralatan.

Untuk analisa keuntungan usaha Petra klapertaart, beberapa komponen yang dikaji seperti:

a. Produksi, yaitu jumlah produk klapertaart yang dihasilkan dalam aluminium foil/cup per bulan.

b. Harga, yaitu harga jual produk klapertaart dalam aluminium foil/cup dalam Rupiah.

c. Bahan baku, jumlah bahan baku yang dipakai dalam proses produksi klapertaart per bulan. Dalam hal ini adalah buah kelapa.

d. Bahan penolong, yaitu jumlah bahan penolong yang dipakai selama satu bulan. Dalam hal ini, bahan penolong langsung seperti terigu, susu, gula pasir, margarin, tepung maizena, telur, rhum, kayu manis bubuk, keju, kismis, kenari, dan bahan penolong tak langsung seperti bahan bakar gas, cetakan aluminium foil.

e. Biaya produksi

Besarnya biaya yang dikeluarkan dalam pengolahan klapertaart dalam sebulan. Variabel ini diukur dalam satuan Rupiah per bulan (Rp/bulan), yang terdiri atas:

1). Biaya tetap, meliputi:

a) Biaya penyusutan alat (Rp)

b) Listrik (Rp)

2). Biaya variabel, meliputi:
a) Biaya bahan baku (Rp)
b) Biaya penolong ( $\mathrm{Rp})$
c) Upah tenaga kerja (Rp/bulan)

d) Biaya pengemasan:

(1) cetakan aluminium foil (Rp/cup)

(2) dus

(3) kantong plastik

(4) sendok plastik

f. Modal, barang/alat produksi dan uang yang dipakai dalam pengolahan klapertaart (Rp).

g. Penerimaan, nilai yang diperoleh dari total produksi dikalikan dengan harga yang berlaku (Rp/bulan).

h. Pemasaran produk.

i. Total biaya adalah jumlah keseluruhan biaya yang dikeluarkan untuk usaha Petra klapertaart yang merupakan penjumlahan antara biaya tetap dengan biaya variabel (Rp/bulan).

j. Keuntungan adalah selisih antara penerimaan (hasil penjualan produk Petra klapertaart dikurangi dengan total biaya $(\mathrm{Rp})$. Analisis ini dihitung berdasarkan keuntungan yang diperoleh dalam Rp/bulan.

\section{Metode Analisis Data}

a. Untuk mengetahui profil/karakteristik usaha Petra klapertaart dianalisis secara deskriptif.

b. Untuk mengetahui besarnya keuntungan yang diperoleh dari usaha Petra klapertaart, digunakan rumus:

$$
\pi=T R-T C
$$

Keuntungan $(\pi)=$ Total Penerimaan (TR) - Total Biaya (TC)

c. Untuk mengetahui apakah usaha Petra klapertaart menguntungkan atau tidak, digunakan Rasio R/C yaitu perbandingan antara penerimaan dengan biaya yang dikeluarkan untuk produksi.

Dimana :

$$
\text { Rasio }: R / C=\frac{(P y \cdot Y)}{F C+V C}
$$

$\mathrm{R} / \mathrm{C}=$ Perbandingan Total

Penerimaan dan Total Biaya

$C($ Cost $) \quad=$ Biaya yang dikeluarkan selama proses produksi

$R$ (Revenue) $\quad=$ Penerimaan yang diterima 


$$
\begin{array}{ll}
P y(\text { Price }) & =\text { Harga jual } \\
\mathrm{Y} & =\text { Hasil produksi } \\
F C(\text { Fixed Cost }) & =\text { Biaya Tetap } \\
V C(\text { Variable Cost }) & =\text { Biaya Variabel } \\
\text { Apabila: } & \\
\mathrm{R} / \mathrm{C}>1, \text { berarti usaha mengalami keun- } \\
\text { tungan } \\
\text { R/C }=0 \text {, berarti usaha tidak mengalami ke- } \\
\text { untungan dan kerugian } \\
\text { R/C }<1 \text {, berarti usaha mengalami kerugian }
\end{array}
$$

d. Untuk mengetahui besarnya nilai penyusutan pada setiap barang atau peralatan yang dipakai, menggunakan rumus:

Penyusutan per bulan = Harga perolehan : umur ekonomis

\section{HASIL DAN PEMBAHASAN}

\section{PROFIL USAHA}

\section{Sejarah dan Deskripsi Umum Usaha Petra Klapertaart}

Petra klapertaart merupakan salah satu jenis usaha industri rumah tangga yang bergerak di bidang pengolahan makanan. Dalam proses produksi, usaha ini menggunakan buah kelapa sebagai bahan baku. Buah kelapa diolah menjadi salah satu kuliner yang terkenal dari kota Manado, yaitu kue Klapertaart. Pemakaian nama Petra diambil dari nama Gereja Pantekosta yang berlokasi di depan usaha ini. Usaha Petra klapertaart diresmikan pada tanggal 6 Mei 2014 oleh bapak Andreas B. Mamesah bersama istrinya, di samping sebagai pendeta juga merupakan pemilik yang turut ambil bagian dalam mengelola usaha ini, ibu Chichi Mamesah, berumur 45 tahun, dan berpendidikan terakhir Sarjana dari salah satu universitas di Jogjakarta. Bapak Andreas berasal dari Manado dan ibu Chichi berasal dari Jakarta. Berawal dari seorang teman yang memotong pohon-pohon kelapa dan tidak bermaksud untuk menggunakannya jadi memberikan sekarung penuh berisi buah kelapa pada ibu Chichi. Dari buah-buah kelapa pemberian tersebut, diolah dengan bahan lain menjadi kue klapertaart. Ibu Chichi meminta bantuan saudara untuk diajari resep pembuatannya. Setelah mampu membuat klapertaart, selama enam bulan sebelum dibukanya usaha Petra, Ibu Chichi sudah mulai menjual hasil klapertaart buatannya. Produksi klapertaart masih berdasarkan pada pesanan, seperti pesanan dari para kolega yang ingin dibelikan klapertaart, saat Ibu Chichi hendak mengunjungi kota tujuan tempat mereka tinggal. Tanggapan para kolega sangat puas akan hasil klapertaart buatan ibu Chichi. Sejak itu, ibu Chichi membuat sendiri klapertaartnya, karena menurutnya, untuk membeli klapertaart, harganya lebih mahal apabila dibandingkan diolah sendiri.

Sebelum adanya bantuan dana dari Kementerian Pertanian, kegiatan produksi klapertaart masih tergantung pada pesanan (belum berproduksi secara tetap), belum menggunakan tenaga kerja (dilakukan oleh ibu Chichi sendiri), belum ada struktur organisasi, peralatan juga masih belum tersedia lengkap seperti show case, dan penggunaan modal masih terbatas untuk produksi klapertaart setiap pesanan. Karena peminat klapertaart buatannya mulai bertambah, maka timbul keinginan untuk membuka usaha klapertaart. Namun, untuk menjalankan usaha, Petra klapertaart membutuhkan modal yang lebih besar, seperti pembelian bahan baku, pembelian peralatan maupun dalam proses produksi. Melalui Kementerian Pertanian, pemilik Petra klapertaart yang juga merupakan ketua organisasi pada usaha ini, menyusun dan mengusulkan proposal Rencana Usaha Lembaga Mandiri yang Mengakar di Masyarakat (LM3) kepada Kuasa Pengguna Anggaran (KPA) setelah disahkan oleh tim teknis. Dalam pemanfaatan dana bantuan modal usaha agribisnis untuk LM3, ketua membuka rekening atas nama "Petra". Kuasa Pengguna Anggaran meneliti rencana usaha Petra yang akan dibiayai. Selanjutnya, diajukan surat permintaan pembayaran langsung. Setelah diuji dan disetujui, diterbitkan surat perintah untuk pembayaran langsung. Lalu menandatangani surat perjanjian kerjasama. Kemudian, diterbitkan surat perintah membayar dari Kuasa Pengguna Anggaran kepada Kantor Pelayanan Perbendaharaan Negara setempat untuk dilakukan pembayaran langsung ke rekening usaha 
Petra. Setiap bulan usaha ini menyampaikan laporan realisasi penggunaan anggaran sesuai rencana usaha dan dilakukan survey oleh petugas setiap 3 bulan. Keseluruhan dana sepenuhnya dimanfaatkan dan tidak ada pengembalian dana. Petra klapertaart berada di bawah naungan Gereja Bethel Tabernakel Petra Manado.

Ada tiga aneka rasa yang disajikan oleh Petra Klapertaart, yaitu rasa original, ubi jalar, dan rasa durian. Usaha ini berlokasi di Jalan Babe Palar nomor 80, kecamatan Wanea kota Manado, dengan luas usaha yang berukuran sekitar $5 \mathrm{~m}$ x $6 \mathrm{~m}$. Karena usaha yang ditempati adalah milik sendiri, jadi tidak mengeluarkan biaya untuk sewa tempat dan beroperasional setiap hari dari pagi pukul 09.00 hingga sore pukul 17.00 WITA. Di luar tempat usaha, pemilik menggunakan spanduk sebagai pendukung usahanya untuk papan nama usaha dan iklan berupa ajakan untuk menarik pelanggan. Sedangkan di dalam ruangan usaha, terdapat sebuah oven, meja untuk mempersiapkan klapertaart yang dibeli pelanggan dan dua buah show case tempat klapertaart dipajang. Di dinding tempat usaha, tergantung sebuah piagam penghargaan dari pemerintah kota Manado dan ijin yang dikeluarkan dari dinas kesehatan dengan nomor 1524/D.03/Kes/VIII/2014.

Pelanggan Petra klapertaart pada umumnya, pembeli yang hendak mengirimkan pada orang yang berada di luar kota Manado. Ini dikarenakan oleh sulitnya mendapatkan kue klapertaart khas Manado di tempat mereka tinggal seperti Yogyakarta, Jakarta, Batam dan Singapura. Untuk para kolega, seringkali memesan klapertaart pada saat ibu Chichi akan berkunjung ke tempat mereka. Tidak jarang Ibu Chichi menyanggupi permintaan pembelian klapertaart dengan ukuran dan harga sesuai dengan pesanan pelanggan. Usaha ini tidak melayani makan di tempat, jenis pelayanannya adalah take away (dibungkus).

\section{Struktur dan Organisasi Manajemen}

Struktur organisasi dalam usaha Petra klapertaart masih tergolong sederhana, yaitu terdiri dari ketua, sekertaris dan juga bendahara. Pemilik usaha memantau serta mengarahkan segala aktivitas dari organisasi usaha ini. Pemilik merangkap sebagai ketua yang bertugas dalam memimpin jalannya produksi, sedangkan sekretaris bertugas mencatat segala keperluan usaha, dan bendahara bertanggungjawab pada keuangan usaha Petra klapertaart. Sekretaris dan bendahara merupakan anggota jemaat dari gereja Petra yang juga turut mengambil bagian dalam proses produksi. Dalam menjalankan struktur organisasi ini, mereka tidak dibayarkan upah tenaga kerja.

\section{Gambar 1. Struktur organisasi usaha Petra klapertaart}

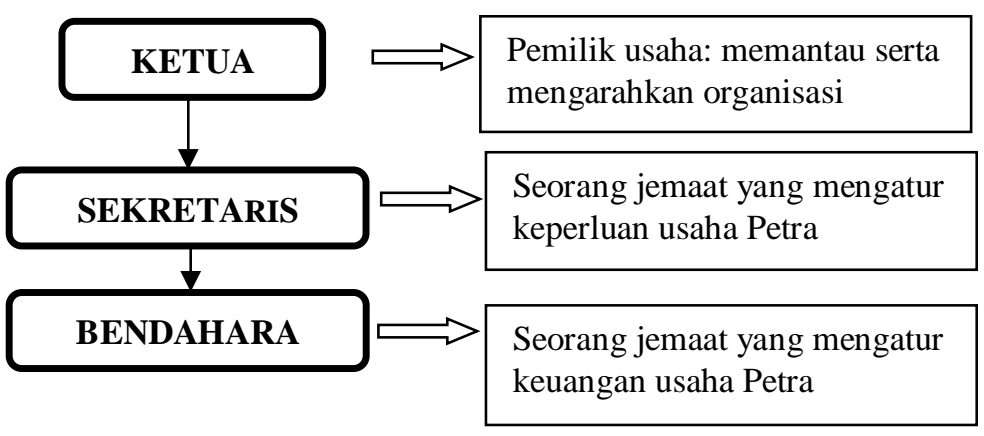

Sumber : Petra klapertaart, 2015

\section{Modal}

Modal pada usaha Petra klapertaart merupakan bantuan dari Kementerian Pertanian. Setelah melewati beberapa prosedur yang ada, usaha ini menjadi usaha yang dipilih Lembaga Mandiri yang Mengakar di Masyarakat (LM3) untuk diberikan bantuan modal berupa dana. Dari modal yang didapatkan, Petra klapertaart menggunakannya untuk pembelian perlengkapan yang dibutuhkan, dekorasi tempat usaha, peralatan, pengurusan ijin usaha juga bahan untuk produksi dalam menjalankan usaha ini. Dana yang diberikan seluruhnya dimanfaatkan usaha ini, tanpa adanya pengembalian dana.

\section{Produk, Jenis Produk dan Harga Klapertaart Petra}

Produk pada usaha Petra klapertaart terdapat variasi rasa, ukuran, dan harga yang ditawarkan. Variasi rasa yang diproduksi adalah original, ubi jalar, dan durian. Harga untuk klapertaart dengan rasa ubi jalar ditambahkan Rp.5.000/cup, sedangkan rasa durian ditambahkan Rp.10.000/cup, 
karena ada tambahan biaya dalam pembuatan adonan yang menambahkan bahan penolong langsung seperti ubi jalar dan durian. Untuk rasa ubi jalar akan tersedia, apabila bahan penolong ubi jalar juga tersedia di pasar. Begitu juga dengan rasa durian, biasanya akan tersedia pada saat musim panen durian. Petra klapertaart juga menerima pesanan ukuran sesuai dengan permintaan pembeli.

Tabel 1. Variasi rasa, ukuran dan harga klapertaart Petra

\begin{tabular}{lcrrr}
\hline \multirow{2}{*}{ No. } & \multirow{2}{*}{ Ukuran } & \multicolumn{3}{c}{ Harga (Rp) } \\
\cline { 3 - 5 } & & Original & Ubi jalar & Durian \\
\hline 1. & $7,5 \times 6,5 \times 3,8 \mathrm{~cm}$ & 15.000 & 20.000 & 25.000 \\
2. & $12,6 \times 6,4 \times 4 \mathrm{~cm}$ & 45.000 & 50.000 & 55.000 \\
3. & $19 \times 18,5 \times 4 \mathrm{~cm}$ & 65.000 & 70.000 & 75.000 \\
4. & $20 \times 20 \times 4 \mathrm{~cm}$ & 135.000 & 140.000 & 145.000 \\
5. & $22 \times 22 \times 4 \mathrm{~cm}$ & 150.000 & 155.000 & 160.000 \\
\hline \multicolumn{2}{l}{ Sumber : Petra klapertaart } & 2015
\end{tabular}

Sumber : Petra klapertaart, 2015

\section{Jumlah Produksi Klapertaart Petra}

Tujuan dari membangun usaha ini adalah memproduksi klapertaart sesering mungkin sehingga mendapatkan keuntungan yang semaksimal mungkin dan mendayagunakan tenaga kerja yang berasal dari jemaat Petra agar dapat menambah pemasukan jemaat, khususnya untuk pembangunan gereja Petra.

Berdasarkan hasil penelitian, jumlah produksi selama bulan September 2015 adalah sebanyak 12 kali, rata-rata jumlah setiap kali produksi sebanyak 2 resep. Dalam 1 kali produksi dengan 2 resep menghasilkan 29 cup aluminium foil. Sehingga jumlah produksi yang didapatkan dalam bulan September 2015 adalah sebanyak 348 cup aluminium foil. Semuanya tersaji dengan rasa original, karena tidak tersedianya bahan penolong ubi jalar dan durian. Pada bulan tersebut, tidak terdapat pesanan khusus dari pembeli dan semua produk klapertaart yang dihasilkan laku terjual di tempat usaha. Rincian jumlah yang diproduksi untuk setiap ukuran dapat dilihat pada Tabel 2.
Tabel 2. Jumlah produksi klapertaart Petra padabulan September 2015

\begin{tabular}{lccc}
\hline No. & Jenis ukuran & $\begin{array}{c}\text { Jumlah per } \\
\text { produksi (cup) }\end{array}$ & $\begin{array}{c}\text { Jumlah produksi } \\
\text { sebulan }(\text { cup })\end{array}$ \\
\hline 1. & $7,5 \times 6,5 \times 3,8 \mathrm{~cm}$ & 8 & 96 \\
2. & $12,6 \times 6,4 \times 4 \mathrm{~cm}$ & 6 & 72 \\
3. & $19 \times 18,5 \times 4 \mathrm{~cm}$ & 6 & 72 \\
4. & $20 \times 20 \times 4 \mathrm{~cm}$ & 6 & 72 \\
5. & $22 \times 22 \times 4 \mathrm{~cm}$ & 3 & 36 \\
\hline & Total & 29 & 348 \\
\hline
\end{tabular}

Sumber: Petra klapertaart, 2015

\section{Proses Pembuatan Klapertaart Petra}

Kegiatan mengolah bahan baku berupa kelapa menjadi kue klapertaart, melalui beberapa tahap yang dilakukan oleh tenaga kerja dengan menggunakan fasilitas produk yang disediakan. Proses produksi klapertaart cukup mudah dilakukan karena alat-alat yang digunakan masih sederhana.

Sebelum memulai produksi, diperhatikan dulu peralatan dan bahan-bahan yang akan digunakan sudah tersedia dengan baik. Ada beberapa tahap dalam proses produksi klapertaart, diawali dengan mempersiapkan buah kelapa untuk dikupas sabutnya, batok kelapa dibelah, air kelapa dituang, lalu daging kelapa dikeluarkan untuk dicuci, dipotong, kemudian direndam ke dalam air kelapa, agar kelapa tidak menghitam. Kenari dicuci kemudian dipotong-potong jadi bagian yang kecil. Kismis direndam dalam air hangat sebentar. Kuning telur dipisah dengan putih telur. Kuning telur dikocok. Tepung terigu dicampur dengan tepung maizena. Gula pasir dan susu dilarutkan dengan api sedang hingga mendidih, kemudian dimasukkan margarin lalu diaduk dengan kuning telur. Kayu manis bubuk dan rum diaduk hingga rata. Buah kelapa dimasukkan ke dalam adonan, lalu diaduk kembali. Kemudian adonan tersebut dituang ke dalam cetakan aluminium foil, dan dimasukkan ke dalam oven dengan suhu $150-160^{\circ} \mathrm{C}$ selama 15 menit. Telur dicampur dengan gula pasir, lalu dikocok hingga mengembang kaku, adonan topping disemprotkan ke atas adonan yang telah setengah matang dan ditaburkan kismis dan kenari cincang, lalu dioven kembali selama 20 menit hingga matang. Untuk menambah hiasan, ditaburkan keju parut, kismis dan kayu manis bubuk di atas kue. Klapertaart dibiarkan dingin dulu sebelum dimasukkan ke dalam show case agar klapertaart tidak rusak. Tahapan proses produksi pada Petra klapertaart dapat dilihat pada Gambar 2. 
Gambar 2. Proses Produksi Klapertaart Petra

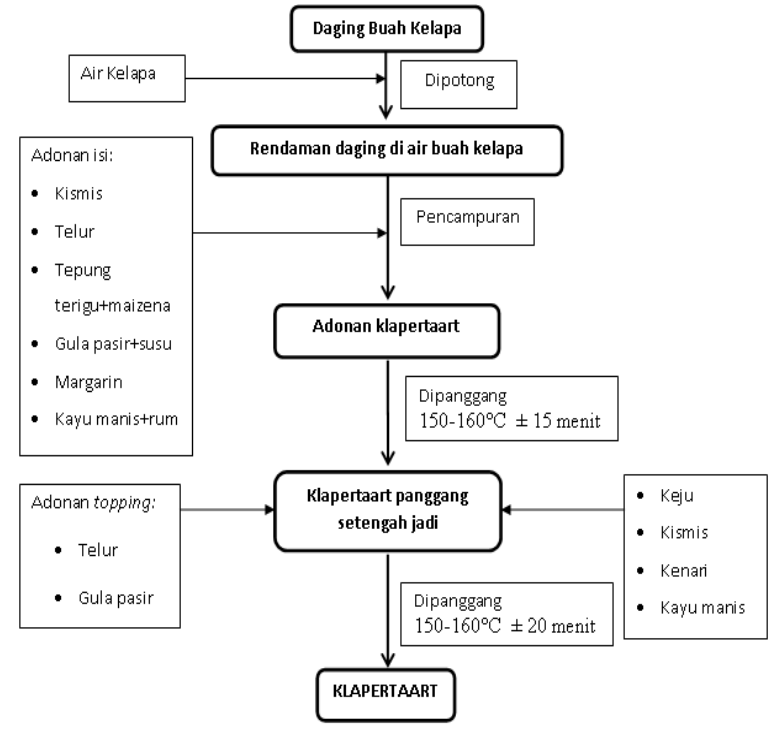

Bahan Baku dan Bahan Penolong

Hasil penelitian menunjukkan bahwa bahan yang diperlukan dalam pembuatan klapertaart adalah buah kelapa sebagai bahan baku dan bahan penolongnya yaitu gula pasir, susu, margarin, tepung terigu, tepung maizena, telur, rum, kayu manis bubuk, keju, kismis dan kenari. Untuk mendapatkan variasi rasa, klapertaart ditambahkan buah durian dan ubi jalar. Karena buah durian sulit didapatkan, maka untuk rasa durian hanya akan tersedia pada saat musim durian. Begitu juga dengan rasa ubi jalar yang akan tersedia, apabila bahannya tersedia di pasar. Kendala kurang tersedianya bahan baku buah kelapa maupun bahan penolong seperti ubi jalar dan durian, terkadang menyebabkan kegiatan produksi pada Petra klapertaart menjadi terganggu.

Buah kelapa yang sudah tersedia, langsung diproduksi menjadi klapertaart. Jadi, tidak ada penyimpanan bahan baku. Untuk mendapatkan bahan baku, pemilik memperolehnya dari supplier, Pasar Segar Paal 2 di kota Manado, yang mengantarkan langsung ke tempat usaha Petra klapertaart, sedangkan bahan penolong sering diperoleh dari swalayan dan di pasar. Pemilik usaha menjalin hubungan kerjasama dengan pedagang langganannya, sehingga kebutuhan bahan baku tersedia. Pada satu resep pembuatan klapertaart, jumlah bahan baku kelapa yang digunakan sebanyak 10 buah kelapa. Berdasarkan penelitian, jumlah pemakaian bahan baku pada bulan September 2015 sebanyak 240 buah kelapa. Untuk harga satuan buah kelapa adalah Rp.5.000. Dalam bulan tersebut, dilakukan 12 kali produksi dengan dua resep, sehingga biaya yang dikeluarkan untuk pembelian bahan baku kelapa oleh Petra klapertaart sebesar Rp. 1.200.000.

Adapun bahan penolong yang digunakan dalam pembuatan klapertaart seperti yang dapat dilihat pada Tabel 3.

Tabel 3. Jumlah penggunaan bahan penolong bulan September 2015

\begin{tabular}{ccccc}
\hline $\begin{array}{c}\text { Bahan } \\
\text { penolong }\end{array}$ & $\begin{array}{c}\text { Per satu } \\
\text { resep } \\
\text { (adonan) }\end{array}$ & $\begin{array}{c}\text { Pemakaia } \\
\text { n sebulan } \\
*)\end{array}$ & $\begin{array}{c}\text { Harga } \\
\text { satuan } \\
(\mathrm{Rp})\end{array}$ & $\begin{array}{c}\text { Total } \\
(\mathrm{Rp} / \mathrm{bulan} \\
)\end{array}$ \\
\hline Gula pasir & $1 \mathrm{Kg}$ & $24 \mathrm{Kg}$ & 13.000 & 312.000 \\
Susu & $1 \mathrm{kaleng}$ & $24 \mathrm{kaleng}$ & 10.500 & 252.000 \\
Margarin & $250 \mathrm{gr}$ & $6 \mathrm{Kg}$ & 45.000 & 270.000 \\
Tepung terigu & $250 \mathrm{gr}$ & $6 \mathrm{Kg}$ & 12.000 & 72.000 \\
Tepung & $300 \mathrm{gr}$ & $7.200 \mathrm{gr}$ & 4.000 & 96.000 \\
maizena & & & & \\
Telur & $25 \mathrm{butir}$ & $600 \mathrm{butir}$ & 2.000 & 1.200 .000 \\
Kayu manis & $2 \mathrm{sdt}$ & $50 \mathrm{gr}$ & 10.000 & 10.000 \\
bubuk & & & & \\
Kismis & $1 \mathrm{Kg}$ & $24 \mathrm{Kg}$ & 85.000 & 2.040 .000 \\
Kenari & $1 \mathrm{Kg}$ & $24 \mathrm{Kg}$ & 125.000 & 3.000 .000 \\
Rhum & $1 \mathrm{botol}$ & $12 \mathrm{botol}$ & 11.000 & 264.000 \\
& $(60 \mathrm{ml})$ & $(60 \mathrm{ml})$ & & \\
Keju & $150 \mathrm{gr}$ & $3.600 \mathrm{gr}$ & 18.000 & 216.000 \\
\hline Total & & & & $\mathbf{7 . 7 3 2 . 0 0 0}$ \\
\hline
\end{tabular}

Sumber : Petra klapertaart, 2015

*)Keterangan :12 kali produksi

Bahan penolong pada Tabel 3 merupakan bahan yang diperlukan dalam pembuatan klapertaart secara langsung. Adapula bahan penolong tidak langsung yang dipersiapkan untuk pengemasan, antara lain wadah tempat klapertaart disajikan dalam aluminium foil, dus, sendok plastik, kantong plastik, dan pemakaian bahan bakar gas. Untuk persediaan bahan penolong tak langsung dapat dilihat pada Tabel 4.

Karena bahan baku dan bahan penolong langsung tidak bertahan lama, maka persediaannya tidak banyak agar tidak rusak. Bahan penolong langsung disediakan untuk seminggu. Sedangkan untuk bahan penolong tidak langsung disediakan kurang lebih untuk pemakaian selama satu bulan. 
Tabel 4. Persediaan bahan penolong tak langsung

\begin{tabular}{clcc}
\hline No. & Bahan penolong tak langsung & $\begin{array}{c}\text { Jumlah } \\
(\mathrm{pcs})\end{array}$ & $\begin{array}{c}\text { Harga } \\
\text { satu- } \\
\text { an } \\
(\mathrm{Rp})\end{array}$ \\
\hline 1. & Aluminium foil $7,5 \times 6,5 \times 3,8 \mathrm{~cm}$ & 100 & 1.050 \\
2. & Aluminium foil $12,6 \times 6,4 \times 4 \mathrm{~cm}$ & 100 & 2.200 \\
3. & Aluminium foil $19 \times 18,5 \times 4 \mathrm{~cm}$ & 100 & 2.800 \\
4. & Aluminium foil $20 \times 20 \times 4 \mathrm{~cm}$ & 100 & 3.250 \\
5. & Aluminium foil $22 \times 22 \times 4 \mathrm{~cm}$ & 50 & 4.400 \\
6. & Dus $15 \times 15 \times \mathrm{cm}$ & 300 & 800 \\
7. & Dus $20 \times 20 \times 7 \mathrm{~cm}$ & 100 & 1.150 \\
8. & Dus $22 \times 22 \times 8 \mathrm{~cm}$ & 50 & 1.200 \\
9. & Sendok plastik (untuk cup kecil) & 100 & 500 \\
10. & Kantong plastik sedang & 300 & 200 \\
11. & Kantong plastik besar & 200 & 300 \\
12. & Bahan bakar gas & 1 tabung & 20.000 \\
\hline
\end{tabular}

Sumber : Petra klapertaart, 2015

\section{Produk Yang Paling Sering Dihasilkan}

Berdasarkan data dari pemilik usaha Petra klapertaart, maka didapatkan produk yang sering dihasilkan pada periode Januari 2015 hingga September 2015 adalah klapertaart original. Dari produksi 3.118 cup klapertaart, rasa original sebanyak 2.495 cup, untuk klapertaart dengan rasa durian sebanyak 325 cup, sedangkan untuk rasa ubi jalar sebanyak 298 cup. Untuk klapertaart dengan rasa durian tidak selalu tersedia, karena tergantung dari musim durian sehingga buah durian sulit untuk didapat. Sama halnya dengan ketersediaan bahan ubi jalar yang tidak selalu tersedia. Untuk persentase produk yang dihasilkan, dapat dilihat pada Tabel 5.

\section{Tabel 5. Persentase Produk Yang Paling Sering} Dihasilkan

\begin{tabular}{cccc}
\hline No. & Rasa & $\begin{array}{c}\text { Jumlah produk } \\
\text { (cup) }\end{array}$ & $\begin{array}{c}\text { Persentase } \\
(\%)\end{array}$ \\
\hline 1. & Original & 2.495 & 80 \\
2. & Durian & 325 & 10,5 \\
3. & Ubi jalar & 298 & 9,5 \\
\hline & JUMLAH & $\mathbf{3 . 1 1 8}$ & $\mathbf{1 0 0}$ \\
\hline
\end{tabular}

Sumber : Petra klapertaart, 2015

\section{Tenaga Kerja}

Usaha Petra klapertaart menggunakan 2 orang tenaga kerja yang berasal dari anggota jemaat gereja Petra, jadi tidak dikerjakan sendiri oleh pem- ilik usaha. Masing-masing tenaga kerja dibayar sebesar Rp.100.000 setiap kali selesai produksi klapertaart. Setiap tenaga kerja memiliki tugas yang sama dari awal proses produksi hingga produksi selesai.

Produksi klapertaart selama bulan September 2015, dilakukan tiga kali dalam seminggu yang dalam satu bulan dilakukan 12 kali produksi klapertaart. Masing-masing tenaga kerja dibayar sebesar Rp. 1.200 .000 pada bulan tersebut. Jadi, besarnya biaya yang harus dikeluarkan pada bulan September 2015 untuk upah dua orang tenaga kerja adalah Rp. 2.400.000,-

\section{Bangunan dan Peralatan Yang Digunakan}

Bangunan yang digunakan Petra klapertaart adalah milik pribadi, jadi tidak perlu mengeluarkan biaya untuk sewa tempat usaha. Adapun peralatan yang digunakan untuk menunjang proses produksi klapertaart seperti show case (tempat dipajangnya klapertaart yang sudah jadi), panci, meja, pisau, mesin oven, sendok kayu, loyang, kompor, dan gas tabung.

\section{Pemasaran}

Pemasaran pada usaha Petra klapertaart adalah Zero-level channel, yaitu pemasaran yang berhubungan langsung dengan konsumen. Klapertaart dijual oleh pemilik usaha secara langsung kepada pembeli. Menurut pemilik usaha, apabila klapertaart didistribusikan ke supermarket dapat memakan waktu sekitar dua minggu untuk mendapatkan hasil penjualan klapetaart dari supermarket tersebut. Karena itu, pemilik usaha ini belum tertarik untuk memasarkannya di luar tempat usahanya. Selain itu juga usaha ini masih tergolong baru dan berskala kecil. Pemasaran usaha Petra klapertaart dapat dilihat pada Gambar 3.

\section{Gambar 3. Saluran usaha pemasaran klaper- taart Petra}

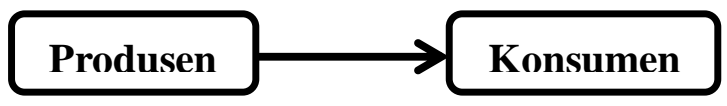




\section{ANALISIS EKONOMI USAHA PETRA KLAPERTAART}

\section{Biaya Produksi}

Biaya produksi terdiri dari biaya tetap dan biaya variabel yang digunakan untuk memproduksi klapertaart. Dalam kegiatan produksi akan dapat dinilai hasil yang diperoleh dari biaya yang dikeluarkan selama produksi berlangsung. Adapun data yang dianalisis yaitu biaya produksi selama bulan September 2015, terdapat pada ulasan berikut.

\section{Biaya Tetap}

Biaya tetap merupakan biaya yang tidak mengalami perubahan pada jumlahnya meskipun volume kegiatan meningkat atau menurun di dalam batas tertentu. Biaya tetap pada penelitian ini, dihitung dari biaya penyusutan alat dan biaya pemakaian listrik. Besarnya biaya penyusutan dihitung dari jumlah keseluruhan peralatan yang berjumlah 9 macam. Untuk melihat lebih jelas alat-alat yang digunakan dan besar penyusutan dapat dilihat pada Tabel 6.

Tabel 6. Biaya penyusutan peralatanusaha Petra klapertaart

\begin{tabular}{|c|c|c|c|c|c|c|}
\hline No & $\begin{array}{c}\text { Peralata } \\
\mathbf{n}\end{array}$ & $\begin{array}{l}\text { Jmlh } \\
\text { Brng }\end{array}$ & $\begin{array}{c}\text { Harga } \\
\text { Awal } \\
\text { (Rp) }\end{array}$ & $\begin{array}{c}\text { Lama } \\
\text { Pakai } \\
\text { (bulan) }\end{array}$ & $\begin{array}{c}\text { Penyus } \\
\text { utan } \\
\text { (Rp) }\end{array}$ & $\begin{array}{c}\text { Biaya } \\
\text { Tetap } \\
(\text { Rp) }\end{array}$ \\
\hline 1. & Oven & 1 & 3.090 .000 & 60 & 51.500 & 51.500 \\
\hline 2. & Panci & 3 & 300.000 & 60 & 5.000 & 15.000 \\
\hline 3. & $\begin{array}{l}\text { Show case } \\
\text { tinggi }\end{array}$ & 1 & 3.650 .000 & 60 & 60.833 & 60.833 \\
\hline 4. & $\begin{array}{l}\text { Show case } \\
\text { rendah }\end{array}$ & 1 & 2.899 .000 & 60 & 48.316 & 48.316 \\
\hline 5. & Kompor & 1 & 400.000 & 60 & 6.666 & 6.666 \\
\hline 6. & Pisau & 1 & 85.000 & 24 & 3.541 & 3.541 \\
\hline 7. & $\begin{array}{l}\text { Sendok } \\
\text { kayu }\end{array}$ & 1 & 25.000 & 12 & 2.083 & 2.083 \\
\hline 8. & Loyang & 4 & 35.000 & 24 & 1.458 & 5.832 \\
\hline 9. & Meja & 1 & 450.000 & 60 & 7.500 & 7.500 \\
\hline & Total & & & & & 201.271 \\
\hline
\end{tabular}

Sumber : Petra klapertaart, 2015 (data diolah)

Penyusutan peralatan yang diperoleh adalah sebesar Rp. 201.271. Biaya penyusutan per bulan, dihitung berdasarkan harga awal pembelian peralatan dibagi dengan umur ekonomis.

Adapun biaya pemakaian listrik untuk penyimpanan klapertaart dalam show case 160 watt, yang dikeluarkan oleh pemilik usaha Petra klapertaart pada September 2015. Besarnya biaya listrik dihitung sebagai berikut:

Biaya Listrik $(\mathrm{Rp}) \quad=$ Daya/1.000 $\times$ Jam Pakai $\mathrm{x}$ Hari Pakai x Harga $/ \mathrm{kwh}$

$=160 / 1.000 \times 24 \times 30 \times 800$

$=0,16 \times 24 \times 30 \times 800$

$=92.160 \times 2$ showcase

$=$ Rp. 184.320

Dalam sebulan biaya pemakaian listrik yang harus dikeluarkan untuk 2 buah show case adalah Rp. 184.320,-

Jadi, total biaya tetap usaha Petra klapertaart adalah sebesar Rp.821.320, yang dihasilkan dari penjumlahan biaya penyusutan peralatan dan biaya pemakaian listrik.

\section{Biaya Variabel}

Biaya variabel adalah biaya yang dikeluarkan untuk faktor produksi yang memiliki sifat berubah-ubah dan akan mempengaruhi besarnya volume produksi atau yang direncanakan. Biaya variabel dalam penelitian ini adalah biaya bahan baku, biaya pengemasan, biaya bahan bakar, dan biaya tenaga kerja yang dihitung selama bulan September 2015.

A. Biaya Bahan Baku

Usaha Petra klapertaart memiliki bahan baku yang terdiri dari bahan baku utama kelapa. Sesuai dengan pengambilan data selama bulan September 2015, dibutuhkan bahan baku kelapa sebanyak 240 buah kelapa dengan harga Rp.5.000/buah. Sehingga pengeluaran bahan baku oleh usaha ini adalah Rp.1.200.000,-

B. Biaya Bahan Penolong

Bahan penolong langsung merupakan bahan yang digunakan dalam pencampuran adonan seperti gula pasir, susu, margarin, tepung terigu, tepung maizena, telur, rum, kayu manis bubuk, keju, kismis, dan kenari. Biaya yang dikeluarkan untuk pemakaian bahan penolong langsung, pada bulan September 2015 sebesar Rp.7.732.000,-

C. Biaya Bahan Bakar

Bahan bakar yang digunakan adalah bahan bakar gas untuk proses pemasakan klaper- 
taart. Dalam pemasakan klapertaart membutuhkan $3 \mathrm{~kg}$ gas elpiji dengan harga Rp. 20.000/tabung yang bisa dipakai untuk 3 kali produksi sebanyak 6 resep. Jadi, pemakaian bahan bakar gas pada periode September 2015 adalah sebanyak 12 tabung gas elpiji $3 \mathrm{Kg}$ sebesar Rp. 240.000,-

D. Biaya Tenaga Kerja

Berdasarkan penelitian, penggunaan tenaga kerja pada usaha Petra klapertaart ada 2 orang dengan pekerjaan yang sama dalam proses produksi. Tenaga kerja diupah Rp.100.000/orang untuk setiap kali produksi. Pada bulan September 2015, biaya tenaga kerja yang harus dikeluarkan untuk 2 orang tenaga kerja adalah sebesar Rp.2.400.000,-

E. Biaya Pengemasan

Untuk memenuhi suatu permintaan, usaha Petra klapertaart melakukan pengemasan menggunakan aluminium foil, dus, sendok plastik (khusus ukuran 7,5 x 6,5 x 3,8 cm), dan kantong plastik sedang dan besar.

Pemakaian dus dan kantong plastik disesuaikan dengan kebutuhan pembeli. Perhitungan biaya pengemasan yang dikeluarkan pada bulan September 2015, sebagai berikut:

Jumlah pemakaian dus:

$$
\begin{aligned}
\text { Dus } 15 \times 15 \times 7 \mathrm{~cm} & =168 \text { cup } \times \mathrm{Rp} .800 \\
& =\mathrm{Rp} .134 .400 \\
\text { Dus } 20 \times 20 \times 7 \mathrm{~cm} & =144 \text { cup } \times \mathrm{Rp} .1 .150 \\
& =\mathrm{Rp} .165 .600 \\
\text { Dus } 22 \times 22 \times 8 \mathrm{~cm} & =36 \text { cup } \times \mathrm{Rp} .1 .200 \\
& =\mathrm{Rp} .43 .200
\end{aligned}
$$

Total biaya pemakaian dus sebesar Rp.343.200,-

Jumlah pemakaian kantong plastik:

$\begin{aligned} \text { Plastik sedang } & =240 \text { cup x } \\ & =\mathrm{Rp} .48 .000 \\ \text { Plastik besar } & =108 \text { cup } \mathrm{x} \text { Rp.300 } \\ & =\text { Rp. } 32.400\end{aligned}$

Total biaya pemakaian kantong plastik sebesar Rp.80.400,-
Jumlah cup aluminium foil yang dipakai dalam bulan September 2015 sebanyak 348 cup aluminium foil, yaitu :

cup $7,5 \times 6,5 \times 3,8 \mathrm{~cm}=96$ cup $\times$ Rp. 1.050 $=\mathrm{Rp} .100 .800$

cup $12,6 \times 6,4 \times 4 \mathrm{~cm}=72$ cup $\times \mathrm{Rp} .2 .200$ $=\mathrm{Rp} .158 .400$

cup $19 \times 18,5 \times 4 \mathrm{~cm} \quad=72$ cup $\times$ Rp. 2.800 $=$ Rp. 201.600

cup $20 \times 20 \times 4 \mathrm{~cm} \quad=72$ cup $\times \mathrm{Rp} .3 .250$

$=\mathrm{Rp} .234 .000$

cup $22 \times 22 \times 4 \mathrm{~cm} \quad=36$ cup $\times$ Rp. 4.400

$=\mathrm{Rp} .158 .400$

Total biaya pemakaian cup aluminium foil sebesar Rp.853.200,-

Pemakaian sendok plastik sebanyak 96 pcs dengan harga Rp.500/pcs = Rp.48.000

Jadi, total biaya pengemasan untuk pemakaian aluminium foil, sendok khusus cup kecil, dus, dan kantong plastik, yang dikeluarkan pada bulan September 2015 adalah sebesar Rp.1.324.800,-

Pada Tabel 7 dapat dilihat perincian biaya variabel (variable cost) yaitu pengeluaran yang tidak tetap pada Petra klapertaart selama bulan September 2015.

Tabel 7. Biaya variabel Petra klapertaart periode September 2015

\begin{tabular}{clc}
\hline No. & \multicolumn{1}{c}{ Biaya variabel } & Jumlah $(\mathrm{Rp})$ \\
\hline 1. & Bahan baku & 1.200 .000 \\
2. & Bahan penolong & 7.732 .000 \\
3. & Biaya bahan bakar gas & 240.000 \\
4. & Biaya tenaga kerja & 2.400 .000 \\
5. & Biaya pengemasan & 1.324 .800 \\
\hline \multicolumn{3}{c}{ Total } \\
\hline
\end{tabular}

Sumber : Petra klapertaart, 2015

\section{Biaya Total}

Perhitungan total biaya produksi klapertaart merupakan penjumlahan biaya tetap dengan biaya variabel yang meliputi biaya bahan baku, bahan penolong, biaya listrik, tenaga kerja, bahan bakar gas, dan biaya pengemasan. Pada usaha Petra klapertaart ini mempunyai biaya tetap meliputi biaya 
penyusutan peralatan dan biaya pemakaian listrik sebesar Rp.385.591, sedangkan biaya variabel sebesar Rp.12.896.800. Sehingga total biaya yang dikeluarkan untuk proses produksi selama September 2015 yaitu sebesar Rp.13.282.391,-. Untuk lebih jelas dapat dilihat pada Tabel 8 .

Tabel 8. Total biaya produksi usaha Petra klapertaart bulan September 2015

\begin{tabular}{lll}
\hline No. & \multicolumn{1}{c}{ Uraian biaya } & \multicolumn{1}{c}{ Nilai $(\mathrm{Rp})$} \\
\hline 1. & Biaya tetap & \\
& Biaya penyusutan alat & 201.271 \\
& Biaya listrik & 184.320 \\
$2 . \quad$ & Biaya variabel & \\
& Bahan baku & 1.200 .000 \\
& Bahan penolong & 7.732 .000 \\
& Biaya bahan bakar gas & 240.000 \\
& Biaya tenaga kerja & 2.400 .000 \\
& Biaya pengemasan & 1.324 .800 \\
\hline & Total Biaya & $\mathbf{1 3 . 2 8 2 . 3 9 1}$ \\
\hline
\end{tabular}

Sumber : Petra klapertaart, 2015 (data diolah)

Perhitungan total biaya produksi klapertaart Petra

Total Biaya = Total Biaya Tetap + Total Biaya Variabel

$=$ Rp.385.591 + Rp. 13.282.391

$=$ Rp.13.667.982

\section{Penerimaan}

Penjualan dari 348 cup aluminium foil klapertaart yang dihasilkan pada September 2015, diperinci sebagai berikut:

Total penerimaan $=$ total produksi $\mathrm{x}$ harga yang berlaku (/cup).

cup 7,5 x 6,5 x 3,8 cm ; 96 cup $\times$ Rp. $15.000=$

Rp.1.440.000

cup $12,6 \times 6,4 \times 4$ cm ; 72 cup $\times$ Rp. $45.000=$

Rp.3.240.000

cup $19 \times 18,5 \times 4$ cm; 72 cup $\times$ Rp. $65.000=$

Rp.4.680.000

cup $20 \times 20 \times 4$ cm; 72 cup $\times \mathrm{Rp} .135 .000=$

Rp.9.720.000

cup $22 \times 22 \times 4$ cm; 36 cup $\times$ Rp. $150.000=$

Rp.5.400.000
Total penerimaan usaha Petra klapertaart untuk semua ukuran cup yang terjual adalah Rp.24.480.000,--

\section{Keuntungan}

Berdasarkan data yang diperoleh, keuntungan usaha Petra klapertaart dapat dilihat dengan menghitung total yang diterima dari hasil penjualan klapertaart dikurangi dengan total biaya yang dikeluarkan.

Keuntungan $=$ Total Penerimaan - Total Biaya

$$
=\text { Rp.24.480.000 - Rp.13.282.391 }
$$

$=$ Rp.11.197.609,-

Jadi, keuntungan yang diperoleh usaha Petra klapertaart pada bulan September 2015 adalah sebesar Rp.11.197.609,-

\section{Rasio $\mathbf{R} / \mathbf{C}$}

Analisis R/C merupakan perbandingan penerimaan dan dan biaya produksi yang dalam penelitian ini bertujuan untuk mengetahui berapa besar tingkat keuntungan dari usaha Petra klapertaart.

$$
\begin{aligned}
\mathrm{R} / \mathrm{C} & =\frac{24 \cdot 480 \cdot 000}{13.282 .391} \\
& =1,84
\end{aligned}
$$

Hasil analisis ini memiliki arti bahwa biaya total yang dikeluarkan sebesar Rp.13.282.391,- memperoleh hasil penjualan sebesar 1,84 kali lipat sehingga layak diusahakan .

\section{KESIMPULAN DAN SARAN}

\section{Kesimpulan}

Usaha Petra klapertaart merupakan usaha berskala kecil yang menggunakan bahan baku buah kelapa untuk diolah menjadi klapertaart dan menjadi salah satu anggota dari Lembaga Mandiri yang Mengakar di Masyarakat (LM3) yang mendapatkan bantuan modal. Setelah mendapatkan bantuan modal dari Kementerian Pertanian, dapat disimpulkan bahwa dalam kegiatan produksi meningkat karena tidak hanya tergantung pada pesanan, tetapi diproduksi untuk dipasarkan. Kegiatan proses produksi pemilik usaha dibantu oleh dua orang tenaga kerja yang berasal dari jemaat gereja Petra. Pemasaran dilakukan oleh pemilik usaha yang berhadapan langsung dengan kon- 
sumen untuk menjual klapertaart yang dihasilkan. Berdasarkan hasil penelitian, banyaknya produksi pada bulan September 2015 yaitu 12 kali produksi yang dibuat 2 resep pada setiap kali produksi, menghasilkan 348 cup aluminium foil klapertaart, memperoleh keuntungan dengan rasio $\mathrm{R} / \mathrm{C}>1$ yaitu sebesar 1,84 artinya pada bulan September 2015 usaha Petra mengalami keuntungan sehingga usaha ini layak dilanjutkan.

\section{Saran}

Berdasarkan hasil penelitian, maka saran yang dapat diberikan dalam kemajuan usaha Petra klapertaart yaitu perlunya meningkatkan promosi agar lebih dikenal masyarakat salah satunya dengan membuat iklan yang disebarkan berupa brosur, dilengkapi denah agar calon pembeli dengan mudah menemukan tempat usaha Petra klapertaart, dan membuat kemasan yang lebih menarik. Selain itu, serta memperluas kerjasama agar meningkatkan pemasaran, seperti menjualnya di lokasi lain, bukan hanya pada lokasi penjualan di Rike. Untuk mengatasi kendala kurang lancarnya ketersediaan bahan baku maupun bahan penolong yang terkadang menyebabkan Petra klapertaart tidak bisa melakukan produksi klapertaart dengan lancar, maka disarankan agar pemilik usaha dapat memperluas kerjasama dengan beberapa supplier yang dapat menyediakan bahan baku dan bahan penolong secara lancar.

\section{DAFTAR PUSTAKA}

Ahyari, Agus. 2002. Manajemen Produksi Perencanaan Sistem Produksi. Edisi Keempat. BPFE. Yogyakarta.

Angipora, P. Marius. 1999. Dasar-Dasar Pemasar-an. Raja grafindo persada. Jakarta.

Anonim. 1983. Simposium Nasional Agroindustri I, Jurusan Teknologi Industri Pertanian. Fakultas Teknologi Pertanian. Institut Pertanian Bogor. 2000. Profil Usaha Kecil dan Menengah Tidak Berbadan Hukum.BPS. Manado.
2013. Tabel Luas Tanaman Perkebunan Menurut Propinsi Dan Jenis Tanaman.www.bps.go.id/link tabel statis. 2014. Lembaga Mandiri Yang Mengakar Di Masyarakat.dinpertan.grobogan.go.id 2015. Deskripsi Kelapa. id.m.wikipedia.org/wiki/kelapa.

2015. Klapertaart. id.m.wikipedia.org/wiki/klapertaart

Assauri, Sofyan. 1995. Manajemen Pemasaran, Dasar, Konsep, dan Strategi. PT. Raja Grafindo. Jakarta.

Griffin, R. 2006. Business 8th edition. New Jersey, Prentice Hall.

Kawoka, Yestelin. 2015. Analisis Studi Kelayakan Usaha Christine Klapertaart di Kairagi Weru Manado.Skripsi Fakultas Pertanian.Universitas Sam Ratulangi Manado.

Kotler, P. dan Gary Amstrong. 2001. Prinsip-Prinsip Pemasaran. Jilid 1 Edisi 8.Prenhallindo. Jakarta.

Mursyidi. 2008. Akuntansi Biaya. Cetakan Pertama. Refika Aditama. Bandung.

Nicholson, W. 1994.Teori Ekonomi Mikro I. PT. Raja Grafindo. Jakarta.

Rumapea, Nesly. 2015. Profil Usaha Sop Buah ICAdi Boulevard Manado. Skripsi Fakultas Pertanian. Universitas Sam Ratulangi Manado.

Siahaan. 1996. Pola Pengembangan Industri. Jakarta [ID]: Departemen Perindustrian.

Soekartawi. 1995. Analisis Usahatani. Universitas Indonesia.Press. Jakarta.

Soewono, L. 2005. Pemanfaatan Teknologi Pascapanen dalam Pengembangan Agroindustri.Prosiding Seminar Nasional Teknologi Inovatif Pascapanen untuk Pengembangan Industri Berbasis Pertanian.Balai Besar Penelitian dan Pengembangan Pascapanen Pertanian. Bogor.

Stanton, William J. 2001. Prinsip Pemasaran. Erlangga. Jakarta.

Terry, G. R.1978. Principle of Management,7th. Ed., Irwin Inc :Homewood Illinois, Richard.

Wirakartakusumah, M. A. 1997. Telaah Perkembangan Industri Pangan di Indonesia. Jurnal Pangan. Vol. VIII No. 1.Bulog.Jakarta. 